\title{
Effect of alkaline ph on sealing ability of white mineral trioxide aggregate
}

\author{
Mehrdad Lotfi ${ }^{1}$, Sepideh Vosoughhosseini ${ }^{2}$, Mohammadali Saghiri ${ }^{3}$, Vahid Zand ${ }^{4}$, Hamid Reza Yavari ${ }^{4}$, Soo- \\ dabeh Kimyai ${ }^{5}$, Masoumeh Mehdipour ${ }^{6}$, Bahram Ranjkesh ${ }^{7}$, Hadi Mokhtari ${ }^{4}$, Amin Salemmillani ${ }^{4}$, Sirvan \\ Doosti $^{8}$
}

\author{
${ }^{1}$ DMD, MSc. Associate Professor, Research Center for Pharmaceutical Nanotechnology, Tabriz University (Medical Sciences), \\ Tabriz, Iran \\ ${ }^{2}$ DMD, MSc. Associate Professor. Department of Oral and Maxillofacial Pathology, Dental Faculty, Tabriz University (Medical \\ Sciences), Tabriz, Iran \\ ${ }^{3}$ BSc, MSc, PhD, Department of Dental Materials, Faculty of Dentistry, Azad University of Medical Sciences, Tehran, Iran \\ ${ }^{4}$ DMD, MSc. Assistant Professor, Department of Endodontics, Dental Faculty, Tabriz University (Medical Sciences), Tabriz, Iran \\ ${ }^{5}$ DMD, MSc. Associate Professor, Department of Operative Dentistry, Dental Faculty, Tabriz University (Medical Sciences), \\ Tabriz, Iran \\ ${ }^{6}$ DMD, MSc. Assistant Professor, Department of Oral Medicine, Dental Faculty, Tabriz University (Medical Sciences), Tabriz, Iran \\ ${ }^{7}$ DMD. Private practice, Tabriz, Iran \\ ${ }^{8}$ DMD, Post graduate student, Department of Endodontics, Dental Faculty, Tabriz University (Medical Sciences), Tabriz, Iran
}

\section{Correspondence:}

Department of Oral and Maxillofacial Pathology, Dental Faculty, Tabriz University (Medical Sciences), Golgasht Street, 5166614713, Tabriz, Iranu

svosough.rare@yahoo.com

Received: $18 / 06 / 2010$ Accepted: 11/12/2010
Lotfi M, Vosoughhosseini S, Saghiri MA, Zand V, Yavari HR, Kimyai S, Mehdipour M, Ranjkesh B, Mokhtari H, Salemmillani A, Doosti S. Effect of alkaline ph on sealing ability of white mineral trioxide aggregate. Med Oral Patol Oral Cir Bucal. 2011 Nov 1;16 (7):e1014-6. http://www.medicinaoral.com/medoralfree01/v16i7/medoralv16i7p1014.pdf

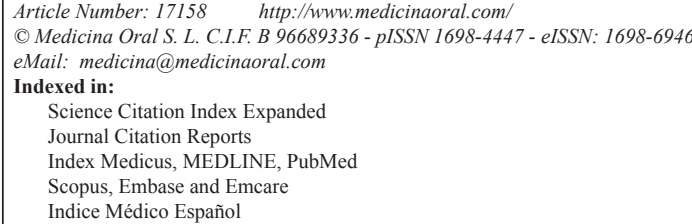

\begin{abstract}
Objectives: The aim of this study was to evaluate microleakage of white mineral trioxide aggregate (WMTA) after its exposure to a range of alkaline environments during hydration.

Study Design: Seventy single-rooted teeth were divided into 4 experimental and 2 control groups. All the teeth were instrumented, and their apices were resected. Root-end cavities were filled with WMTA in the experimental groups. In the control groups, root-end cavities were not filled. Root-end fillings were exposed to alkaline environments with $\mathrm{pH}$ values of 7.4, 8.4, 9.4, or 10.4 for 3 days. Microleakage was evaluated by bovine serum albumin. Evaluations were carried out at 24 -hour intervals for 80 days. Data were analyzed by one-way analysis of variance and a post hoc Tukey test at the 0.05 level of confidence.

Results: The number of days (mean \pm standard deviation) needed for color change at $\mathrm{pH}$ values of 7.4, 8.4, 9.4, and 10.4 were $78.53 \pm 5.68,80.00 \pm 0.00,68.93 \pm 19.00$, and $34.46 \pm 12.73$, respectively. The time needed for leakage to occur was significantly shorter in samples stored at a $\mathrm{pH}$ value of $10.4(\mathrm{P}<0.001)$.

Conclusions: Within the limits of this study, it can be concluded that $\mathrm{pH}$ values greater than 9.4 may jeopardize the sealing ability of WMTA during hydration.
\end{abstract}

Key words: Microleakage, $p H$ value, white mineral trioxide aggregate. 


\section{Introduction}

Mineral Trioxide Aggregate (MTA) is a mixture of Portland cement, bismuth oxide, and trace amounts of other metallic oxides (1). MTA has been used for vital pulp therapy, repair of furcal and lateral perforations that are isolated from the oral environment, as an apical plug in open apex nonvital teeth, and as a root-end filling material during apical surgery (2). In certain clinical cases, freshly mixed MTA might be applied in the presence of inflammation, and the surface of the material is exposed to an acidic environment in such cases (3). A previous study showed that an acidic environment significantly decreases the sealing ability of white mineral trioxide aggregate (WMTA) (4).

MTA has been advocated for use in the immediate obturation of open apex teeth $(2,5-12)$. The treatment procedures in open apex teeth include placement of calcium hydroxide paste as an inter-appointment intra-canal medicament to eliminate or reduce bacterial contamination before placement of MTA (2). Hachmeister et al. (13) found that calcium hydroxide does not affect the sealing ability of gray MTA (GMTA); however, Stefopoulos et al. (14) showed that calcium hydroxide pretreatment, adversely affects sealing ability of WMTA, leading to the assumption that calcium hydroxide interferes with WMTA at the apical region. He suggested that the residual calcium hydroxide might merely be a mechanical obstacle to MTA adaptation to the root canal walls or might chemically react with WMTA. However, the effect of alkaline $\mathrm{pH}$ values on sealing ability of WMTA is still unknown. Therefore, the aim of the present study was to compare microleakage of WMTA at different alkaline $\mathrm{pH}$ values by the use of bovine serum albumin.

\section{Material and Methods}

\section{Tooth Preparation}

Seventy single-rooted mature human anterior teeth, extracted for periodontal reasons, were used in this study and stored in phosphate-buffered saline solution until used. An ultrasonic device was used to clean root surfaces. Radiographic images in two mesiobuccal and buccolingual directions were checked to exclude calcified canals after discarding cracked teeth. The teeth were randomly divided into 4 experimental groups of 15 and 1 negative and 1 positive control groups of 5 . After preparing standard access cavities with a round diamond bur under water spray, the root canals were cleaned and shaped with step-back technique using K-files (Maillefer, Ballaigues, Switzerland). The root canals were prepared to \#35 as master apical file. Two $\mathrm{mL}$ of $2.5 \% \mathrm{NaOCl}$ was used as intra-canal irrigation during instrumentation; coronal flaring was performed with Gates-Glidden drills \#2 and \#3 in the coronal third of the canals. The canals were obturated with guttapercha (VDW, Munich, Germany) without sealer using cold lateral compaction technique after complete drying with paper points. A diamond bur in a high-speed handpiece under copious water spray was used to cut 3 $\mathrm{mm}$ of apical part of the roots perpendicular to the long axis. Three-mm-deep circular root-end cavities were prepared with the Kis-3D microsurgical ultrasonic instrument (Spartan, Fenton, MO), rinsed with saline, and dried with paper points. A well-fitted microcondenser was used to condense WMTA (Tooth-colored Formula; Dentsply, Tulsa Dental, Tulsa, OK, USA), which was prepared according to manufacturer's instructions in the experimental groups. The thickness and adequate placement of WMTA were checked with radiographic images. Root-end cavities in the positive and negative control groups were left unfilled. Three wet pieces of gauze that had been soaked in synthetic tissue fluid (STF), prepared as $1.7 \mathrm{~g}$ of $\mathrm{KH}_{2} \mathrm{PO} 4,11.8 \mathrm{~g}$ of $\mathrm{Na}_{2} \mathrm{H}-$ $\mathrm{PO}_{4}, 80.0 \mathrm{~g}$ of NaCl , and $2.0 \mathrm{~g}$ of $\mathrm{KCl}$, were buffered in potassium hydroxide at $\mathrm{pH}$ values of 8.4, 9.4, and 10.4, respectively, and placed in 3 separate vials. Each experimental group was placed in 1 vial for 3 days and rootend materials were exposed to pieces of gauze. Gauze pieces were replaced every day with fresh ones to ensure an adequate alkaline environment. One wet piece of gauze was soaked in STF without buffering and put in 1 vial, and the remaining samples in the experimental group were placed in it for 3 days. All the samples were incubated at $37^{\circ} \mathrm{C}$. The roots in the experimental and positive control groups were coated with 2 layers of nail varnish. The apical and coronal surfaces were not coated. In the negative control group, the entire root surfaces were covered with 2 layers of nail varnish.

Leakage of Bovine Serum Albumin

Valois and Costa (15) model was used to perform leakage study. In brief, the end of Eppendorf tubes was cut, and the protruded apices of roots through the end of the tubes were sealed with cyanoacrylate glue. Rubber stoppers of $10-\mathrm{mL}$ glass vials were punched and the tubes were inserted through it. Five $\mathrm{mL}$ of distilled water and $1 \mathrm{~mL}$ of $22 \%$ bovine serum albumin (BSA) solution (Sigma Chemical Co, St Louis, MO) were used to fill the glass vial and the Eppendorf cylinder, respectively. All the specimens were stored in a humidor at $37^{\circ} \mathrm{C}$ for 80 days. The water and BSA were changed daily during the experimental period. Protein detection was performed every day with a reagent. The number of days leading to color conversion of the protein reagent was calculated as apical leakage.

One-way analysis of variance and Tukey test were performed at the 0.05 level of confidence to analyze data.

\section{Results}

After one day, the specimens in the positive control group showed color conversion. No color change was observed in the negative control group during the experiment. At 
$\mathrm{pH}$ values of $7.4,8.4,9.4$, and 10.4 , the number of days (mean \pm standard deviation) needed for color conversion were $78.53 \pm 5.68,80.00 \pm 0.00,68.93 \pm 19.00$, and 34.46 \pm 12.73 , respectively. There were significant differences between the groups $(\mathrm{P}<0.004)$. Tukey test revealed a significant difference between the samples stored at a $\mathrm{pH}$ value of 10.4 and other groups $(\mathrm{P}<0.001)$. In other words, the time needed for leakage was significantly shorter in samples stored at a $\mathrm{pH}$ value of 10.4 .

\section{Discussion}

In the present study, we tried to examine the effect of alkalinity on microleakage properties of WMTA by exposing it to the alkaline-soaked pieces of gauze. Potassium hydroxide was used as a source of alkalinity because the deleterious effect of calcium hydroxide and sodium hydroxide on hydration and shrinkage of Portland cement had been studied and because of the similarity of MTA and Portland cement, we wanted to evaluate the effect of a new source of alkalinity on WMTA. Use of bovine serum albumin in this study for 80 days as a method of leakage evaluation has been confirmed by researchers as a reliable method $(4,15)$.

Researchers who have used MTA as an apical barrier have not reported any problems since they have not considered using calcium hydroxide $(16,17)$. Hachmeister et al. (13) reported that medication with calcium hydroxide does not affect sealing ability of gray MTA (GMTA). Stefopoulos et al. (14) suggested two reasons for the negative effect of calcium hydroxide on sealing ability of WMTA. They suggested that the residual calcium hydroxide might merely be a mechanical obstacle to adaptation of MTA to root canal walls or it might chemically react with WMTA. In this study, we eliminated the effect of mechanical obstacle by refusing to place the alkaline source directly into the root canals and just apical surfaces of WMTA were exposed to different alkaline $\mathrm{pH}$ values. Saghiri et al. (18) showed that at $\mathrm{pH}$ values of 8.4 and 9.4 the amount of unhydrated WMTA decreases and the surface hardness, as an indicator of the setting process, increases and if WMTA is exposed to $\mathrm{pH}$ values higher than 9.4 adverse effects might result. In this study WMTA showed significantly greater leakage at a $\mathrm{pH}$ value of 10.4; therefore, it appears that microleakage of WMTA has a linear relationship with the amount of unhydrated cement in the presence of high $\mathrm{pH}$ values. It should be pointed out that the aim of this study was to show the effect of alkalinity on microleakage of WMTA; therefore, this study showed that calcium hydroxide which has high alkaline $\mathrm{pH}$ can act as a source of alkalinity and jeopardize the sealing ability of WMTA if it remains in the canals during endodontic treatment. Thus, copious irrigation and more instrumentation should be performed to eliminate residual calcium hydroxide before placement of WMTA as apical plug or root repair material subsequent to root perforation to prevent deleterious effect of alkalinity on sealing ability of WMTA.

\section{References}

References with links to Crossref - DOI

1. Camilleri J, Montesin FE, Brady K, Sweeney R, Curtis RV, Ford TR. The constitution of mineral trioxide aggregate. Dent Mater. 2005;21:297-303.

2. Torabinejad M, Chivian N. Clinical applications of mineral trioxide aggregate. J Endod. 1999;25:197-205.

3. Namazikhah MS, Nekoofar MH, Sheykhrezae MS, Salariyeh S, Hayes SJ, Bryant ST, et al. The effect of $\mathrm{pH}$ on surface hardness and microstructure of mineral trioxide aggregate. Int Endod J. 2008;41:108-16.

4. Saghiri MA, Lotfi M, Saghiri AM, Vosoughhosseini S, Fatemi A, Shiezadeh V, et al. Effect of $\mathrm{pH}$ on sealing ability of white mineral trioxide aggregate as a root-end filling material. J Endod. 2008;34:1226-9.

5. Shabahang S, Torabinejad M, Boyne PP, Abedi H, McMillan P. A comparative study of root-end induction using osteogenic protein-1, calcium hydroxide, and mineral trioxide aggregate in dogs. J Endod. 1999;25:1-5

6. Witherspoon DE, Small JC, Regan JD, Nunn M. Retrospective analysis of open apex teeth obturated with mineral trioxide aggregate. J Endod. 2008;34:1171-6.

7. Levenstein H. Obturating teeth with wide open apices using mineral trioxide aggregate: a case report. SADJ. 2002;57:270-3.

8. Steinig TH, Regan JD, Gutmann JL. The use and predictable placement of Mineral Trioxide Aggregate in one-visit apexification cases. Aust Endod J. 2003;29:34-42.

9. Rafter M. Apexification: a review. Dent Traumatol. 2005;21:1-8. 10. El-Meligy OA, Avery DR. Comparison of apexification with mineral trioxide aggregate and calcium hydroxide. Pediatr Dent. 2006;28:248-53.

11. Gaitonde P, Bishop K. Apexification with mineral trioxide aggregate: an overview of the material and technique. Eur J Prosthodont Restor Dent. 2007;15:41-5.

12. Simon S, Rilliard F, Berdal A, Machtou P. The use of mineral trioxide aggregate in one-visit apexification treatment: a prospective study. Int Endod J. 2007;40:186-97.

13. Hachmeister DR, Schindler WG, Walker WA 3rd, Thomas DD. The sealing ability and retention characteristics of mineral trioxide aggregate in a model of apexification. J Endod. 2002;28:386-90.

14. Stefopoulos S, Tsatsas DV, Kerezoudis NP, Eliades G. Comparative in vitro study of the sealing efficiency of white vs grey ProRoot mineral trioxide aggregate formulas as apical barriers. Dent Traumatol. 2008;24:207-13.

15. Valois CR, Costa ED Jr. Influence of the thickness of mineral trioxide aggregate on sealing ability of root-end fillings in vitro. Oral Surg Oral Med Oral Pathol Oral Radiol Endod. 2004;97:108-11.

16. Matt GD, Thorpe JR, Strother JM, McClanahan SB. Comparative study of white and gray mineral trioxide aggregate (MTA) simulating a one- or two-step apical barrier technique. J Endod. 2004;30:876-9. 17. Al-Kahtani A, Shostad S, Schifferle R, Bhambhani S. In-vitro evaluation of microleakage of an orthograde apical plug of mineral trioxide aggregate in permanent teeth with simulated immature apices. J Endod. 2005;31:117-9.

18. Saghiri MA, Lotfi M, Saghiri AM, Vosoughhosseini S, Aeinehchi M, Ranjkesh B. Scanning electron micrograph and surface hardness of mineral trioxide aggregate in the presence of alkaline $\mathrm{pH}$. $\mathrm{J}$ Endod. 2009;35:706-10.

\section{Acknowledgments}

We would like to thank the office of Vice Chancellor for Research, Tabriz University of Medical Sciences and Dr. Majid Abdolrahimi for their contributions to this research effort. 